\title{
Developing a Career Development Program for Medical Sciences Students: Reflecting “in" and "on” Practice
}

\author{
Ebinepre A. Cocodia ${ }^{1}$ \\ ${ }^{1}$ School of Arts and Sciences, University of Notre Dame Australia, Sydney, Australia \\ Correspondence: Ebinepre A. Cocodia, School of Arts and Sciences, University of Notre Dame Australia, \\ Sydney, NSW, 2007, Australia. E-mail: ebinepre.cocodia@nd.edu.au
}

Received: September 9, 2014

Accepted: October 17, $2014 \quad$ Online Published: November 13, 2014

doi:10.5539/hes.v4n6p24

URL: http://dx.doi.org/10.5539/hes.v4n6p24

\begin{abstract}
Using a reflective practice approach this paper provides an outline of the development of a new career development and counselling program for students within a medical sciences off-campus precinct. Drawing on Schön's (1983) reflective practice framework the aim included reflecting "in" and "on" action during the development and implementation of the program, leading to transformative learning. Client (the student) and counsellor had the opportunity to assess and reframe their views through the incorporation of new knowledge and information. The career development program is based on Krumboltz and Super's theoretical models with a focus on the life stages of career and leisure development throughout the lifespan. The paper concludes that individuals may begin to examine and assess their own skills and abilities by drawing on aspects of reflective practice such as noticing, making sense, making meaning, and finally reaching a stage of self-awareness (Bager-Charleson, 2010). These outcomes may transpire as a result of participation in various skills audit exercises and related activities within a career development program.
\end{abstract}

Keywords: Australia, career development, counselling, medical sciences, student

\section{Introduction}

Career development is described as the process of balancing one's life, work and learning. McIlveen and Patton (2006) pointed out that although various career development theories and practices exist there remains consensus that career development occurs over the individual's life span. The career development process may include vocation assessments, participation in career development programs and sometimes psychometric testing. The emphasis of the career development processes listed above includes needs, interests and abilities of the client.

As the focus of the current paper is career development in the medical sciences it is a good idea to outline what a career in the medical sciences may entail. A graduate career in this field may involve the completion of an initial Bachelor of Science or Associate degree in the medical sciences field. Here, a student spends a significant portion of time learning about the structure and function of the body. In addition, academic studies focus on diseases at the cellular level as well as the whole body. Discipline-related streams may also be narrowed down to include the study of one or more health science areas with an extensive look at understanding the underlying science of medicine. These areas include anatomy, pathology, neuroscience, physiology and pharmacology.

\section{Reflective Practice}

Donald Schön's work provided a backdrop for the development and implementation of this career development and counselling program. Schön (1983) proposed the term reflective practice which involves thinking about one's actions critically to assist practitioners to improve their professional practice. For instance, it is not enough that I have drawn from my knowledge base to develop a career counselling program. The aim is to develop a clear link to professional knowledge and professional practice. Thus when we are able to get to this point we become reflective practitioners (Thompson \& Thompson, 2008).

The reflective practitioner may consider events and practices after conducting a specific task or activity. This is referred to as reflection-on-action. For instance the practitioner may review activities that have occurred such as work processes, discussions with clients, and professional interactions with colleagues. The practitioner may also begin to think about other counselling techniques a client may respond to. The practitioner draws from their knowledge base to determine what makes sense. The key concept is that the practitioner reviews the events after 
it may have occurred so they can learn from these experiences.

The term reflection-in action indicates that the practitioner is assessing and re-assessing while "doing". This means that while an activity is ongoing one may consider and then re-consider responses and decisions while in practice. The goal is to draw from existing knowledge to reach a place of transformative learning.

The current paper provides a platform for reflection-on-practice as it provides a bridge for us to understand the relationship between professional knowledge and professional practice. It also helps to improve our practice while integrating theory to practice. Subsequent sections of this paper provide a background to the development of the career development program. Hence, reflection-in-practice occurred while implementing the program. Reflection-on-practice is further emphasized based on the theoretical framework outlined in subsequent sections of this paper.

\section{The Case for a Career Development Program}

The career development program was largely for students in the final year of a four year training program within a research institute (off-campus). Other participants included recent, first and second year graduate students in addition to early career higher degree graduates. The organization where this program was developed consists of approximately seven hundred researchers and administrative staff. Three other research and medical institutes are affiliated within the precinct. As such, research and administrative tasks are conducted collaboratively. Many of the staff are also joint university academics. The organisation is headed by a senior scientist/professor who reports to a board of nine. The chief operation officer oversees the finance group and other administrative teams including the human resources department. There are 200 students also classified by the human resources department as "staff members" due to human resources contract policy. Within the graduate program are 200 students, 100 are PhD scholars, 60 are MSc students and 40 are in the honors year. Within the student body, some graduate students wear multiple hats due to the fact that they are also practicing medical doctors who completed advanced specialist training and are exploring the possibility of a research career in biomedical science. Others are outstanding science graduates who have successfully gained competitive scholarship to help pay for graduate studies in the medical sciences.

The human resources department provides professional development programs for scientists and administrative staff. However, meetings with the student body indicated that many students did not feel like they were a part of the organisation. This is probably due to the assumption that graduate students are not quite employees. In addition, students reported that the off-campus location made it quite difficult to connect with other students and available career development services readily accessible on many university campuses. This may be because some find it difficult to travel to the main university campus to seek career development assistance. As such, there was a gap, which the present career development program aimed to address.

The nature of career development issues and queries the students presented with served as a guide to developing a comprehensive program. A previous student survey in collaboration with the human resources department suggested that many students viewed their role at the institute as workers as well as students. This may be attributed to the long hours scientists are expected to spend in the laboratory. The perception of oneself as employee emphasises the importance of each student's role and an important career decision. However, understandably, discussions with many of the honors/ fourth year students (and some graduate students) suggested that some students were still not quite certain that they are on the "right" career path. This suggests that while some students may be merely exploring options, others view their current endeavors as a suitable career development process. In addition, on reflection it appeared that some students were tentatively testing the waters, trying to navigate the field and career options available while completing graduate studies. Also, some students indicated that they felt uncertain and alone and a bit removed from the whole research process once they had submitted their final thesis. This may be because they did not have a clear career development plan and are faced with the reality of life after studies.

\section{Theoretical Models for the New Career Development Program}

This career development program draws on Super's $(1980,1990)$ theoretical model which focuses on the life stages of career and leisure development throughout one's lifespan. Factors within the model include evolving self-concept due to values, skills or external/internal conditions. Super's Life-Career Rainbow is of particular significance here as it highlights the importance of life stages and the interaction of career and leisure across all stages of life. This is especially relevant to students as they make significant decisions throughout all six life roles leading to career and leisure changes. This implies that career represents various life roles and activities throughout an individual's lifespan. In addition, Super pointed out that career development may also be influenced by childhood experiences, values, self-awareness, decision-making skills, internal locus of control 
and willingness to explore.

Another theoretical model used is Krumboltz learning theory (Mitchell \& Krumboltz, 1996) as aspects of the theory relates to the current career development proposal. The authors argued that factors which determine career decision-making include genetic endowment, environment, instrumental and associative learning experiences and knowledge of task approach skills. They also emphasised the importance of exploring options, developing new skills and aiding exposure to learning experiences. The authors argued that irrational beliefs may hinder career decision making with beliefs and values influencing career choice. While the use of positive reinforcement and role models may further promote career choice, exploration and learning are also essential.

Significantly, the program includes aspects of Kosine, Steger and Duncan's (2008) Purpose-Centred model. The aim of the career development program includes promoting identity, self-efficacy, metacognition, culture and service as described by the authors. In addition, identity formation includes seeking possible options such as evaluating career concepts while personal stories and social issues are considered. Another element within the model is self-efficacy where the individual's belief in self is at the core of career decision-making. Kosine et al. (2008) described self-efficacy as necessary for "exploring strengths and limitations" (p. 134) while metacognition represents "knowledge of cognition and regulation of cognition" (p. 134). They argued that self-awareness may enhance the career decision-making process, which is consistent with Super and Krumboltz's theories. Hence, self-appraisal abilities may lead to decision-making. Culture is also described as another relevant aspect of the Purpose-Centred model. From a cultural perspective the total way of life of the individual is very important. As such, culture consists of gender, values and socioeconomic situation. Therefore career decision-making may be determined by one or all of these factors. Service indicates that choices may be based on community, and other environmental indicators linked to one's society.

\section{Program Framework}

The career development program draws on the adult framework of the Australian Blueprint for Career Development (ABCD) (Haines, Scott \& Lincoln, 2005). The (ABCD) listed organisational support structures as inclusive of leadership, management, marketing, networks, facilities and resources. Based on this framework, leadership is represented by executive support for the initiative. The career development practitioner's role included managing and tracking program development. Marketing procedures entailed benchmarking, publications and reporting. In addition, the program involved networking with a wide range of scientific and medical sciences recruiters as well as other relevant local and international career development organisations. Facilities were set up to enable students access career information, career development software, and services for career decision-making.

As mentioned, the focus of the career development program included each individual student's needs with an emphasis on specific career goals and aspirations. As such, within the ABCD tertiary education framework international and overseas students are also well supported. Hence, existing international students received specialised career development options relevant to individual interest, country of residence and individual plan for research study completion. Due to cultural differences, aspects of the Australian career development process may vary from each student's expectations. Significantly, the career program explored cultural awareness and identity, social structures and values (Crump, 2001; Kosine, Steger, \& Duncan, 2008). Students who worked well in a laboratory setting but have limited English language ability were targeted for specialised career development counselling from a suitable qualified career counsellor. In addition, activities were developed to help with the transition from thesis submission to working in Australia if desired by each student.

A needs assessment is a preliminary step in planning any program or initiative (May, 1988) and consists of the identification and analysis of issues and gaps. It is also a means of gathering useful information to guide program development while engaging the students in identifying their needs. The current program included an assessment exercise with the help of the student body consisting of a sample group of students. A questionnaire survey was completed with students indicating types of career development programs they would utilize. Some responses overlapped with existing programs and therefore required the development of a collaborative relationship with the on-campus career development practitioner. Students were also asked to indicate by ticking a box which of the listed possible activities they may benefit from. Activities selected included career workshops, resume writing skills, career counselling and career expos. The career program therefore included all of the above-mentioned activities. In addition, career plans (or portfolios) were also included in the program.

\subsection{Workshops}

Workshops are brief educational sessions where information and/or training are provided and usually focus on a specific area of concern. Using a reflective practice approach (Schon, 1983) it was important to reflect "in" and 
"on" action while exploring new sources of knowledge. This I argue may help participants reframe and isolate specific issues and areas for further growth which may be identified. The career development program therefore focused on selected workshop topics during the academic year. Students had the option of attending sessions relevant to individual needs. Subject areas that were tracked as relevant for our students'needs are listed in Table 1.

Table 1. Skill development and work experience activities

\begin{tabular}{ll}
\hline Skill Development & Related Work Experience \\
\hline Putting together a career portfolio & International positions in overseas labs \\
Resume writing skills development & Local and international work experience during the \\
Identifying science and career options after thesis & $\begin{array}{l}\text { summer break } \\
\text { completion/submission }\end{array}$ \\
Strategies for successful job seeking & Leisure/ work-life balance \\
Preparing for an interview & \\
Effective networking & \\
\hline
\end{tabular}

\subsection{Career and Leisure Expos}

In collaboration with selected recruitment firms based in the city centre, recreational organisations and human resources departments of various organisations, the career development practitioner marketed and teamed up with appropriate groups to provide career and related events. The importance of the students' work-life balance was promoted within this program. Pichler (2009) described work-life balance as consisting of all activities in and around one's life. These include employment, parenthood, relationships, childbirth, leisure, relocation and so on. These factors amongst other may influence the students' career and leisure decision-making. The experience of an expo that explores career and leisure may be a suitable learning experience for some candidates. Relevant areas of interest for the students included, biomedical research organisations, the pharmaceutical industry, state and federal government science jobs, academic roles, postdoctoral positions as well as the not-for profit sector.

\subsection{Career and Leisure Counselling}

Career counselling entails obtaining a clear picture of the client, matching their interests, values, abilities and skills to specific occupations (Cochran, 1997). The author pointed out that the role of the career counsellor also includes helping the client decide and then act on that decision. The current career development program therefore consisted of individual and group career counselling sessions. Students made appointments online or email prior to each session.

Leisure is described as one's left-over time after working (Haworth \& Lewis, 2005). The authors argued that although complex, when one manages to enjoy work and leisure they may successfully have a work-life balance and be motivated to conduct other activities. Leisure counselling was promoted as part of this program so students can become more aware of the impact of leisure activities on career choices. Pichler (2009) argued that work-life balance influences career choice. Leitner (2000) added that leisure counselling helps encourage "leisure-well-being". The author suggested the use of leisure inventories during counselling using a developmental-educational approach or remedial-therapeutic approach. The focus of this career development program was the first approach as the remedial approach is described as more suitable for "lower functioning" individuals (Leitner, 2000). This is not consistent with the current program's targeted demographics. This approach involves developing rapport after pre-counselling assessments. Leitner pointed out the counsellor must clarify that concepts of leisure are consistent with the clients' perception of leisure to eliminate misunderstanding. Identifying both leisure goals and needs were determined during individual and group counselling sessions. Issues that emerged included physical activities, spending flexible hours in the lab or even attending a child's school play.

Using the above-mentioned theoretical model, the career development program draws on Super's (1980) theory where the initial aim may involve attempting to identify the level of career maturity. In addition, utilizing Krumboltz theory (1979) enables the counsellor to focus on removing those irrational beliefs that may hinder career decision-making. The client's self-concept is also analyzed by suitable career assessment tools. The counselling process may also include the identification of factors that may further develop life roles throughout 
one's lifespan. The client may be encouraged to explore various options such as working in a research lab overseas or working in a local lab. Alternative choices for each individual student were explored within this context. In addition, Kosine et al.'s (2008) focus on the individual's strengths and interests such as community and service participation was explored during counselling. The consequences of possible decisions were examined while the counsellor noted that the client is ultimately responsible for making their own decisions. Another key area for career growth in this field is exposure to new biomedical research and professional networking opportunities. Each student is encouraged to present research-related papers at seminars and conferences which may provide positive re-enforcement including peer feedback. Some may also receive prizes such as poster or student prizes for their effort. These achievements are usually included in the career portfolios. In addition, the actual steps involved in putting together a portfolio reportedly enhanced individual self-awareness as described by Schon (1983).

\subsection{Career Plan}

Each student was tasked with developing a career portfolio in liaison with the career development consultant. $\mathrm{ABCD}$ (Haines et al. 2005) emphasised the importance of career portfolios as a means of keeping track of career growth and fostering learning. The career development practitioner provided guidance with the belief that the process of developing a career portfolio may further enhance each student's self- awareness (Krumboltz, 1979; Super, 1980). Each career portfolio included an initial assessment, goals, proof of education and training details and other relevant skills. Current employment and individual ongoing professional development and leisure activities were also included. Other contents of the career portfolio are copies of submitted academic writings and manuscripts, papers or journal articles conference proceedings, abstracts, student prizes, evidence of competitive scholarships, referee reports and commendations. Students were advised to include details of any leisure activities which demonstrate a work-life balance. These may include marathons, or charity activities, sport, parenthood, caregiver and other roles which may or may not influence career choices.

\subsection{Evaluation}

Evaluation exercises may assist in the assessment of both outcome and process of any career development program (Haines et al.2005). Keeping track of the current program and evaluating progress at various stages helped make necessary changes and further improvement to the program. Evaluation was conducted using the following approaches:

1) Evaluation information was sought from current and past students who participated in the program from start to finish.

2) A sample of the total student body was initially asked to participate.

3) Surveys were conducted at the end of each workshop.

4) Students who visit the career development practitioner were asked to rate (scale of 1 to 5) the level of assistance received during the session.

5) Student self-assessment.

6) Recruiters who assisted students were asked to provide feedback regarding perception of student-readiness for interviews or work life in general.

The data collection and analysis was conducted in consultation with a statistician. As this is only a reflective paper, future scholarly reports and submissions will focus on data analysis and reporting thus adding to the body of knowledge within the field of career development. The overall aim of this paper is to outline the process of engaging students in career development programs within an off-campus facility.

At the graduate level the career development program also encourages higher degrees supervisors to be part of their student's career development program. For instance, Masters Degree and doctoral thesis supervisors usually select students and see them through 'bumpy patches' of their postgraduate career. This gives the supervisors an insight into their students' capabilities, career and leisure activities and career development during the period of candidature until completion.

\section{Conclusion}

A review of the steps taken to develop and implement a career development program serves as reflective practice approach and a useful tool for learning. This is consistent with reflective practice processes which entails thinking about one's actions critically to help practitioners improve their professional practice (Schon, 1983). By reflecting "in" and "on" action practitioners assess and re-assess existing programs and practices. In addition, integrating theory to practice is a key aspect of reflective practice while the practitioner is also considering and 
re-considering actions and meanings. This career development program was flexibly delivered based on feedback from stakeholders.

The program also gave students the opportunity to notice, reflect, and make meaning of their abilities and skills. Gaining self-awareness provided student and practitioner opportunity to consider any additional self-development options. Significantly, the role of the reflective practitioner also involved thinking analytically and creatively while framing and re-framing within the context of professional practice.

Using various theoretical models within the program allowed for some level of creativity to be drawn from existing knowledge base within a reflective practice framework. The career development program utilized Super's $(1980,1990)$ theoretical model with a focus on the life stages of career and leisure development throughout one's lifespan. Another theoretical model utilized was Krumboltz learning theory (Mitchell \& Krumboltz, 1996; 1979) as it relates to career development within the context of the present framework. Finally, due to the high achieving academic record of the cohort, the program also included aspects of Kosine et al.'s (2008) Purpose-Centred model.

There is a clear need to explore similar programs within other academic disciplines within Australia and internationally. In addition, while the emphasis of this career development program was the medical sciences discipline at an off-campus location, the development processes of comparable program within other academic disciplines may be explored based on the individual need of each organisation

\section{References}

Bager-Charleson, S. (2010). Reflective Practice in Counselling and Psychotherapy. Exeter: Learning Matters.

Cochran, L. (1997). The narrative basis for career counselling. In Career counselling: A narrative approach. Thousand Oaks, CA: SAGE Publications.

Crump, D. (2001). Issues in indigenous education and vocational counselling. Australian Journal of Career Development, 10(3), 20-24. http://dx.doi.org/10.1177/103841620101000305

Haines, C., Scott, K., \& Lincoln, R. (2005). Career development programs for adults. Australian blueprint for career development (pp. 97-105). Miles Morgan Australia Ltd. Retrieved from http://www.dest.gov.au/sectors/career_development/policy_issuesreviews/key_issues/australian_blueprint_f or_career_dev/

Haworth, J., \& Lewis, S. (2005). Work, leisure and well-being. British Journal of Guidance and Counselling, 33(1), 67-79. http://dx.doi.org/10.1080/03069880412331335902

Kosin, N. R., Steger, M. F., \& Duncan, S. (2008). Purpose-centred career development: A strengths-based approach to finding meaning and purpose in careers. Professional School Counselling Journal, 12(2), 133-136. http://dx.doi.org/10.5330/PSC.n.2010-12.133

Krumboltz, J. D. (1979). A social learning theory of career choice. In A. M. Mitchell, G. B. Jones, \& J. D. Krumboltz (Eds.), Social learning theory and career decision making (pp. 19-49). Cranston, RI: Carroll Press.

Leitner, M. (2000). The role of leisure counselling for special populations in facilitating successful adjustment to life in the community. In A. Sivan, \& H. Ruskin (Eds.). Leisure education, community development and populations with special needs (pp. 93-100). Wallingford, UK: CABI Publishing. http://dx.doi.org/10.1079/9780851994444.0093

May, E. (1988). How to conduct a needs assessment. Drug Information Journal, 22(4), 587-597.

McIlveen, P., \& Patton, W. (2006). A critical reflection on career development. International Journal for Educational and Vocational Guidance, 6(1), 15-27. http://dx. 10.1007/s10775-006-0005-1

Mitchell, L. K., \& Krumboltz, J. D. (1996). Krumboltz's learning theory of career choice and counselling. In D. Brown, D. L. Brooks, \& Associates (Eds.), Career choice and development (3rd ed., pp. 233-280). San Francisco, CA: Jossey-Boss Publishers.

Pichler, F. (2009). Determinants of work-life balance: Shortcomings in the contemporary measurement of WLB in large-scale surveys. Social Indicators Research, 92, 449-469. http://dx.doi.org/10.1007/s11205-008-9297-5

Schön, D. (1983).The Reflective Practitioner: How Professionals Think in Action. Basic Books, New York.

Super, D. E. (1980). A life-span, life-space approach to career development. Journal of Vocational Behaviour, 16, 
282-298. http://dx.doi.org/10.1016/0001-8791(80)90056-1

Super, D. E. (1990). A life-span, life-space approach to career development. San Francisco, CA: Jossey-Boss Publishers.

Thompson, S., \& Thompson, N. (2008). The Critically Reflective Practitioner. London, U.K.: Palgrave-Macmillan.

\section{Copyrights}

Copyright for this article is retained by the author(s), with first publication rights granted to the journal.

This is an open-access article distributed under the terms and conditions of the Creative Commons Attribution license (http://creativecommons.org/licenses/by/3.0/). 